\title{
The Influence of Social Supports on Graduate Student Persistence in Biomedical Fields
}

\section{Mica Estrada, "* Qi Zhi, " Ezinne Nwankwo, ${ }^{\ddagger}$ and Robyn Gershon*\|}

${ }^{\dagger}$ Department of Social and Behavioral Sciences, Institute for Health and Aging, and ₹Philip R. Lee Institute for Health Policy Studies, University of California, San Francisco, San Francisco, CA 94118; §onathan and Karin Fielding School of Public Health, University of California, Los Angeles, Los Angeles, CA 90095; "Department of Epidemiology, College of Global Public Health, New York University, New York, NY 10003

\begin{abstract}
Pathways to biomedical careers are not being pursued with equal vigilance among all students. Emerging research shows that historically underrepresented (HU) students who maintain a strong science identity are more likely to persist. However, the influence of social support on persistence is less studied, especially as it relates to science identity among doctoral students. To fill this gap, a 1-year study to assess similarities and differences among $101 \mathrm{HU}$ and majority biomedical doctoral students was conducted to measure the extent to which 1) they report equivalent experiences of social support, science identity, and intentions to persist; 2) their experiences of social support predict intentions to persist 1 year later; and 3) science identity mediates the relationship between social support and intentions to persist in biomedical career pathways. Data were collected using online surveys. Results indicated that science identity significantly mediated the relationship between professional network support and persistence a year later for majority students. In contrast, for HU students, science identity mediated the relationship between instrumental, psychosocial, friend and family support, and persistence a year later. These study results provide evidence that reinforcing mentoring programs and support systems will be beneficial, especially for HU students.
\end{abstract}

\section{INTRODUCTION}

Accompanying the accelerated development of technology and engineering over the past 20 years has been a revolution in the field of biomedical research, leading to new results and discoveries to improve human health. To continue on this trajectory of growth, there is a need for committed and diverse young scholars to continually enter and persist in biomedical fields. Yet there is strong evidence that the pathways to biomedical careers are not being pursued with equal vigilance among all students (National Research Council, 2011). In particular, historically underrepresented (HU) students represent only a small proportion of scholars at every step on the path toward a career as a biomedical research scientist, even though the absolute numbers of $\mathrm{HU}$ students throughout the pipeline has substantially increased. For example, and due in large part to support from the National Institutes of Health (NIH) and the National Science Foundation (NSF), there has been a steady increase in the number of $\mathrm{HU}$ students entering biomedical doctoral programs; in 2000, there were $3444 \mathrm{HU}$ students entering doctoral programs, and by 2013 , this increased by $74 \%$ to 5992 (Meyers et al., 2018). Although retention of these students is high, with dropout rates similar to those of majority students, at $15 \%$, they still represent only a small percentage $(12 \%)$ of all doctorally prepared bioscientists (Meyers et al., 2018). This is also reflected in the very low proportion (less than 10\%) of doctorally prepared HU scholars who become full-time biomedical research faculty (Meyers et al., 2018). And in
Erin L. Dolan, Monitoring Editor

Submitted Feb 1, 2019; Revised May 31, 2019; Accepted Jun 3, 2019

CBE Life Sci Educ September 1, 2019 18:ar39 DOI:10.1187/cbe.19-01-0029

*Address correspondence to: Mica Estrada (mica.estrada@ucsf.edu).

(c) 2019 M. Estrada et al. CBE-Life Sciences Education @ 2019 The American Society for Cell Biology. This article is distributed by The American Society for Cell Biology under license from the author(s). It is available to the public under an Attribution-Noncommercial-Share Alike 3.0 Unported Creative Commons License (http://creativecommons.org/licenses/ by-nc-sa/3.0)

"ASCB®" and "The American Society for Cell Biology $\AA^{\circ}$ are registered trademarks of The American Society for Cell Biology 
spite of gains, HU people remain underrepresented relative to the U.S. population at every stage of the biomedical career pathway (President's Council of Advisors on Science and Technology, 2012).

Market forces unquestionably keep a large proportion of all new graduates out of traditional tenure-track academic research positions, and they are increasingly opting for (or are forced toward) other career paths available to them, including both research-intensive and non-research intensive careers. According to the Biomedical Research Working Group Report, among the 9000 biomedical PhD students who graduated in the United States in 2009, 24\% were employed in academic research (often as postdoctoral fellows), $23 \%$ in teaching at the secondary or graduate level, $18 \%$ in industry, and $6 \%$ in government (NIH, 2012; Rockey, 2012a). Although unemployment for biomedical doctorates is extremely low, a surprisingly high percentage (30\%) exits the field entirely, with many underemployed in jobs that do not require a doctoral degree (Larson et al., 2014). Other doctorally prepared research scientists working in nontraditional careers also contribute to the advancement of research in the field, most notably those working in the pharm-tech industry and others employed in academia in positions that conduct or support research. Sinche and colleagues (2017) report that the vast majority of skills acquired during doctoral training in science, technology, engineering, and mathematics (STEM) are transferable across research and non-research careers. In an earlier report by Nelson and Brammer (2010) that also documented relatively few HU faculty at research universities, the authors conclude that a lack of social support and role models in the academic environment for early-career faculty influences this disparity.

There are many barriers along the arduous path to a biomedical research career for both HU and majority (i.e., white and Asian students represented above population rates) doctoral students, with time and cost arguably the most significant. With an average of 6-7 years to complete a biomedical doctoral degree (Rockey, 2012b) added onto the 4 years spent in undergraduate education, biomedical students typically invest nearly a decade (or more) to obtain specialized research training. In addition to the students' time commitment, the time faculty spend educating biomedical doctoral students is also considerable, including time for course development, lectures, dissertation committees, lab rotations, and advising and mentoring (Smolka et al., 2015). All of this effort also has financial implications-for the student, the universities, the government, and even the general public (in the form of taxes). Training biomedical research scientists is expensive, and research training investments may be lost when doctoral students exit for nonresearch, non-science types of employment. With such high investments from students, faculty, and funding agencies, efforts to understand the factors that promote and ensure these specially trained doctoral students maintain their trajectory are needed. This is especially important with respect to HU students, because they are even more likely to follow alternative career pathways.

\section{Professional Identity and Persistence}

Professional identity, a type of social identity, is influential to social integration and affiliation. Tajfel and Turner (2004) originally introduced the concept of social identity theory as a way to explain why individuals can favor a group (typically their own) and discriminate against another group. This theory posits that each person has a variety of "social selves," that, in turn, individually connects one to various social groups, including people who share common social attributes. A person's gender, ethnicity, religion, age, interests, practices, and activities can define that person's identity group. In addition, there can be a professional identity, which sometimes develops through education, mentorship, or co-curricular involvement. Social identity theory suggests that, when a person identifies with a social group, that person is likely to think, feel, and act in a way consistent with the norms of the group (Kelman, 2006). Without such identification, persons are less likely to do what group members typically do. Thus, when students have high professional identity, they report seeing themselves as members of their professions (e.g., a scientist or engineer), and they are more likely to engage in their professions and persist (Chemers et al., 2011; Estrada et al., 2011).

Recent research on biomedical research career development has started to examine how social factors predict persistence. For example, social identity theory predicts that students who develop a professional identity-for example, by identifying as a scientist-are more likely to adhere to the norms of the professional community and persist in the field. There is growing evidence that confirms this hypothesis (Villarejo and Barlow, 2007; Hurtado et al., 2009; Graham et al., 2013; Estrada, 2014). Mediation analysis from The Science Study tested the tripartite integration model of social influence and found that, as $\mathrm{HU}$ students became more highly identified with the field of science, they were more likely to persist in science careers ( Estrada et al., $2011,2018 b)$. On the basis of data from a semiannual questionnaire, the authors documented the positive effect of scientific self-identity on growth and attainment of performance-approach goals over time, which in turn led to participation in STEM fields (Hernandez et al., 2013). Results from Corwin and colleagues emphasized the importance of science identity as contributing to motivation and confidence for persistence in STEM for both undergraduate and graduate minority students (Corwin et al., 2015), and in a recent National Academies report, science identity was listed as a key outcome of engaging in research that ultimately contributes to retention (National Academies of Sciences, Engineering, and Medicine, 2017).

\section{Social Support and Identity Development}

From the field of higher education, there is evidence that HU students' sense of "belonging" in their academic communities is complex and often obstructed (Hurtado and Carter, 1997). To address the issue of attrition, several studies have shown how social supports from mentors, advisors, peers, and instructor relationships, as well as from discipline-related clubs and societies, contribute toward students persisting in biomedical career pathways (Espinosa, 2011; Estrada et al., 2018a). Research by Mendoza-Denton and colleagues (2006) on race-based rejection concludes that cross-race friendships can provide social support when discrimination occurs and may be particularly helpful to persons with high sensitivity to race-based rejection by increasing coping when confronted with race-related difficult experiences. The influence of specific types of social supports on professional identity development and persistence is less well understood. 


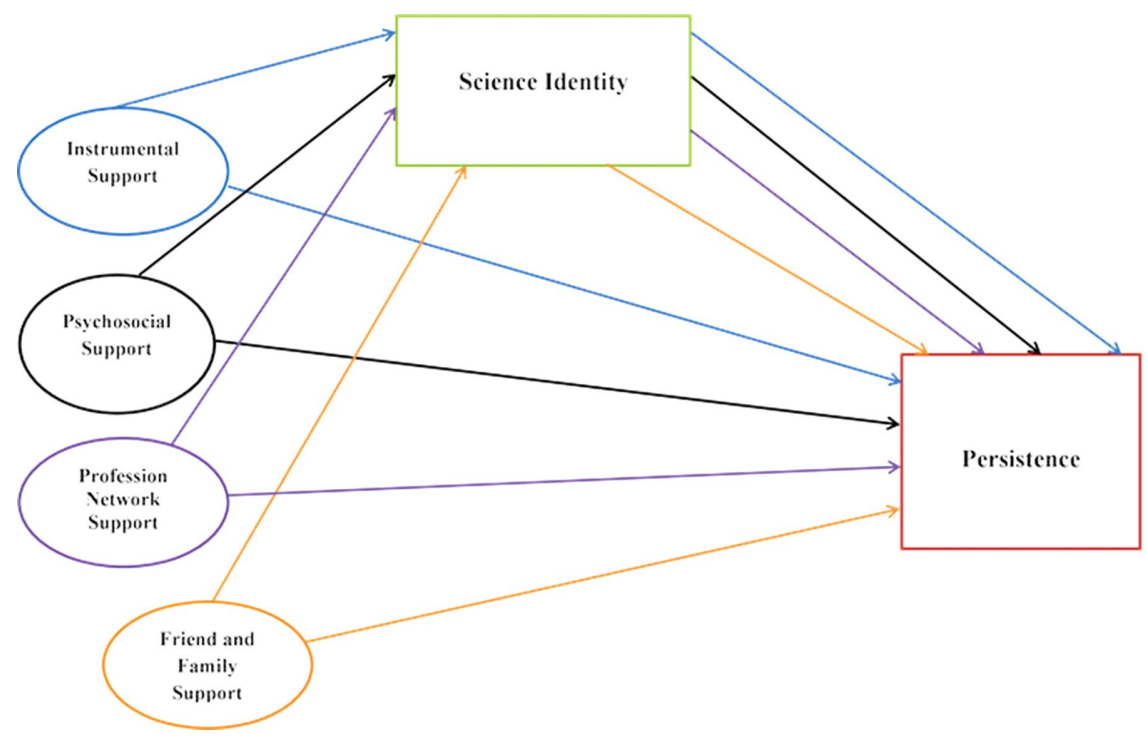

FIGURE 1. Full-study mediation models including four types of social supports, science identity as the mediator, and intentions to persist as the outcome.

Types of Mentorship Support. One of the best-researched social support types is in the context of mentorship. Mentorship typically is used to describe the experience of an experienced professional providing professional development support to a less experienced protégé (Eby et al., 2007). Meta-analyses of mentor-protégé studies have shown that providing instrumental and psychosocial support is important to the protégé experiencing positive outcomes (Eby et al. 2013). Specifically, mentors can provide instrumental support, which includes providing access, visibility, resources, materials, and other forms of concrete support to assist in career progress. Mentors can also provide psychosocial support, whereby the mentor contributes toward a protégé's emotional and personal development (Flaxman et al., 1988; Nakkula and Harris, 2014). An additional form of support that also has been shown to be a part of quality mentorship is providing networking support, which includes helping a protégé broaden and strengthen his or her professional network (Lent et al., 2003b). In some cases, elements of these have been combined to create a composite measure of "quality mentorship" (Hernandez et al., 2017).

Social Support and Professional Identity. For HU STEM students, quality mentorship has been found to increase belonging, discipline identity development, and overall confidence in being a scientist (Lopatto, 2007; Dolan and Johnson, 2009; Chemers et al., 2011; Thiry and Laursen, 2011). Hernandez et al. (2017), using a longitudinal quasi-experimental design, provide evidence that quality mentorship support (not ethnic similarity of mentor to protégé) contributed to retention and persistence of African-American students drawn from 50 different institutions. Estrada and colleagues (2018b) most recently found that mentor social support for HU students impacted student persistence through strengthening science identity. At the same time, research also suggests that HU and majority students may not have similar mentorship experiences or needs. A student's cultural background can influence a whole host of attributes that are valued, including perceptions of science, identity, sense of belonging, and overall experience of a mentor's support (Hurtado et al., 2009; Laursen et al., 2010; Blake-Beard et al., 2011; Graham et al., 2013). There is no quantified research on the relationship between friend and family support on the acquisition of science identity and engagement in biomedical career persistence.

\section{Research Questions}

Despite the growing research in this area, information is sparse on how specific types of social support influence persistence in biomedical fields for doctoral students. To address this gap, we conducted a 1-year longitudinal intervention study of University of California, San Francisco (UCSF), biomedical doctoral students that included groups of HU and majority students. The purpose of this study was to assess similarities and differences among HU and majority biomedical doctoral students regarding the following: First, to what extent do HU and majority doctoral students report equivalent experiences of social support, science identity, and intentions to persist relative to each other? Second, do their experiences of social supports predict intentions to persist in biomedical fields 1 year later? And third, does science identity mediate the relationship between social supports and intentions to persist in biomedical career pathways? This last question will be answered using PROCESS mediation analyses. Figure 1 depicts the full mediation model that was tested to answer the third research question.

\section{METHODS}

\section{Participants}

The data for this paper were collected as part of the Biomedical Research career Identification in Graduate Education (BRIDGE) research project, a longitudinal study designed to determine the effectiveness of professional development interventions on motivation to persist in a research science career; participants included first-year $(n=36)$, second-year $(n=33)$, and thirdyear $(n=32)$ doctoral students enrolled in research-intensive biomedical, social science, or nursing doctoral programs. All students were enrolled in degree programs that specifically provided training for pharm-tech or faculty research careers. In October 2014, a short message of study introduction, selection criteria, and a link to the baseline survey were sent directly to all 442 qualified participants at their university email address. Of these, 322 returned completed surveys. A stratified random sample of 101 participants, including an oversampling of HU students, resulted in a total sample of $55 \mathrm{HU}$ and 46 majority participants. The analytic sample in this paper is from a stratified random sample of students who completed both the firstyear baseline survey and year 1 survey (with a 92\% response rate at year 1 ).

As shown in Table 1, the baseline median age was 28 years for both the majority and HU groups. A large proportion (70\%; $n=32$ ) of participants in the majority group were female, while 
TABLE 1. Demographic characteristics of study participants $(N=101)$

\begin{tabular}{|c|c|c|c|}
\hline \multirow[b]{2}{*}{ Variable } & \multirow[b]{2}{*}{ Category } & \multicolumn{2}{|c|}{$n(\%)^{\mathrm{a}}$ or mean } \\
\hline & & Majority & HUs \\
\hline Age & & 28 & 28 \\
\hline Completion year & & 2018 & 2018 \\
\hline \multirow[t]{3}{*}{ Gender } & Male & $14(30.4)$ & $21(38.2)$ \\
\hline & Female & $32(69.6)$ & $33(60.0)$ \\
\hline & Transgender & 0 & $1(1.8)$ \\
\hline \multirow[t]{4}{*}{ Marital status } & Single & $30(65.2)$ & $44(80.0)$ \\
\hline & Married & $7(15.2)$ & $5(9.1)$ \\
\hline & Living with domestic partner & $9(19.6)$ & $6(10.9)$ \\
\hline & Divorced/widowed & 0 & 0 \\
\hline \multirow[t]{2}{*}{ Ethnicity } & Hispanic & 0 & $30(54.5)$ \\
\hline & Non-Hispanic & $46(100)$ & $25(53.0)$ \\
\hline \multirow[t]{6}{*}{ Race (non-Hispanic) } & White & $28(60.9)$ & $3(12.0)$ \\
\hline & Asian/Asian American & $18(39.1)$ & $5(20.0)$ \\
\hline & African American & 0 & $12(48.0)$ \\
\hline & American Indian & 0 & $3(12.0)$ \\
\hline & Pacific Islander & 0 & $2(8.0)$ \\
\hline & Native Hawaiian & 0 & 0 \\
\hline \multirow[t]{3}{*}{ Past academic experience } & Attended a professional conference & $18(39.1)$ & $20(36.4)$ \\
\hline & Prepared a scientific manuscript ${ }^{\mathrm{b}}$ & $26(56.5)$ & $16(29.1)$ \\
\hline & Prepared a grant application & $26(56.5)$ & $23(41.8)$ \\
\hline \multirow[t]{2}{*}{ Socioeconomic status } & Mean total amount of student loan owed & $\$ 35,001-45,000$ & $\$ 45,001-55,000$ \\
\hline & Mean total amount of debt & $\$ 15,000-25,000$ & $\$ 25,001-35,000$ \\
\hline \multirow[t]{4}{*}{ Difficulty in paying for basic needs } & No difficulty at all & $13(28.3)$ & $16(29.1)$ \\
\hline & Minor difficulty & $19(41.3)$ & $23(41.8)$ \\
\hline & Moderate difficulty & $9(19.6)$ & $10(18.2)$ \\
\hline & A lot of difficulty & $5(10.9)$ & $6(10.9)$ \\
\hline
\end{tabular}

aTotal number for each item might not add up to $N$ due to missing values.

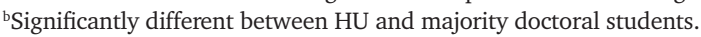

$60 \%(n=33)$ of participants in the HU group were female. Sixty-five percent of the majority students and $80 \%$ of $\mathrm{HU}$ students reported being single, while only $15 \%$ of the majority and $9 \%$ of HU students were married. The remaining participants were living with a domestic partner or a significant other. In the majority group, $61 \%$ of doctoral students identified themselves as white, while 39\% identified as Asian/Asian American (not underrepresented). Both of these groups are statistically overrepresented in biomedical science relative to the U.S. population. In the HU group, $55 \%$ of participants identified themselves as Latinx/Hispanic. The remaining HU students identified as African American (48\%), followed by 12\% American Indian, and $8 \%$ Pacific Islander. In addition, we allowed participants to self-identify themselves as underrepresented. This group included 20\% Asian/Asian American (including disabled and underrepresented first-generation Asian students, such as those from Vietnam or Laos, who are considered underrepresented relative to the population) and $12 \%$ white (disabled, biracial, or self-identified as underrepresented). None of the participants reported being Native Hawaiian. Participant enrollment was evenly distributed among the first, second, and third years, with roughly 30\% enrolled in each year. This enrollment trend was similar for both HU and majority groups. While more than $65 \%$ of participants in the majority group reported their expected doctoral degree completion year to be 2018 or earlier, only $50 \%$ of the participants in the HU group reported that they expected to complete their degrees by 2018 .

\section{Procedures}

The research team was assisted in the development of the baseline survey by university stakeholders (i.e., administrators and staff working with doctoral students), and BRIDGE advisory board members. To ensure the robustness of the survey and survey items, stakeholders and advisory board members assessed the clarity of the questions by participating in pretesting and by providing notes on the content and face validity of the measures. To the greatest extent possible, well-validated psychosocial scales were used. All study procedures had prior review and approval (IRB \#12-10024) from the UCSF Human Research Protection Program.

The survey was administered online using Qualtrics and included a skip mechanism for questions that might not apply to all participants. A modified tailored panel management (Estrada et al., 2014) approach was used at each survey administration, which included four personalized email reminders, compensation (a \$20 e-Amazon gift card), and branding of the BRIDGE study. Of the 101 participants, the response rates for baseline and year 1 were 100 and 92\%, respectively. Additionally, we used a reminder mechanism in Qualtrics, which highlighted any questions missed by the participant. The participants were prompted to either answer or skip the questions.

\section{Measures}

Baseline and year 1 surveys were identical, except that demographic information was only asked at baseline, and the year 1 
survey (administered 1 year later) added two questions regarding career intentions to persist. The survey included questions regarding academic experiences, psychosocial variables, productivity measures, and quality of school life. The results reported here used the baseline measure of social support and year 1 measure of science identity and intentions to pursue a biomedical career.

Instrumental Support. This was a four-item Likert scale, based on the NIH mentoring guideline (NIH, n.d.). Participants were asked to indicate how satisfied ( $1=$ not at all satisfied to $5=$ extremely satisfied) they were with their advisor/principal investigator (PI) regarding a series of mentorship attributes, including "Defining the goals of your doctoral program," "Frequency of meetings," "Quality of communication," and "Feedback on your scientific work" ( $\alpha=0.89)$.

Psychosocial Support. A four-item scale was created based on the NIH mentoring guideline (NIH, n.d.). Participants were asked to indicate how satisfied they were with their advisor/PI from 1 (not at all satisfied) to 5 (extremely satisfied). Statements included "Helping provide professional networking opportunities," "Maintaining a healthy school/work-life balance," "Advice on nonacademic career opportunities," and "Assistance in completing your Individual Development Plan" $(\alpha=0.88)$.

Professional Network Support. This was a two-item scale based on the NIH mentoring guideline (NIH, n.d.). Participants were asked to indicate the extent to which each statement describes their experience and to assign a rating from 1 (not at all) to 5 (to a very large extent). Statements included "Help you to meet other people in your field inside of UCSF" and "Help you to meet other people in your field outside of UCSF" ( $\alpha=0.83)$.

Friend and Family Support. This two-item scale, adapted from Lent's original 14-item Contextual Supports scale (Lent et al. 2003b), asked participants to indicate their level of agreement with statements, each rated from 1 (strongly disagree) to 6 (strongly agree). Statements included "Close friends are proud of the fact that I am pursuing a doctoral degree" and "I feel supported by my partner/family/friends in my pursuit of a doctoral degree" $(\alpha=0.69)$.
Science Identity (Mediator). A five-item scale, adopted from Estrada et al. (2011), asked participants to indicate their level of agreement with statements, each rated from 1 (strongly disagree) to 5 (strongly agree). Statements included "I have a strong sense of belonging to the community of scientists," "I derive great personal satisfaction from working on a team that is doing important research," "I have come to think of myself as a "scientist," "I feel like I belong in my field of science," and "The daily work of a scientist is appealing to me" $(\alpha=0.83)$.

Persistence (Outcome). We adapted an outcome measure from The Science Study (Estrada et al., 2011), using an 11-point Likert scale from 0 (definitely will not/not at all likely) to 10 (absolutely will/likely) to create a five-item "persistence" measure of participants' intentions to pursue careers in science. Specifically, each item asked participants to indicate their intentions to pursue careers in science: "To what extent do you intend to pursue a science-related research career?," "To what extent do you intend to pursue a career in the same field as your doctoral research?," "To what extent do you intend to pursue a career in which you publish scientific findings in peer-reviewed journals?," "To what extent do you intend to pursue a career in which you present papers at conferences?," and "To what extent do you intend to pursue a career in which you write grant applications for funding?" $(\alpha=0.91)$.

\section{Plan of Analysis}

To answer the proposed research questions, we first examined the internal consistency of the scales by calculating Cronbach's alpha. Alphas near or above 0.70 were deemed acceptable (Nunnally and Bernstein, 1994). In addition, we assessed whether the alphas were comparable to previously published alpha scores for our measures of support, science identity, and intention to pursue a biomedical career. We then conducted descriptive analysis on all internally consistent scales and performed chi-square analysis and $t$ tests to note significant differences in any variables and scales between HU and majority students at baseline (see results in Table 2). Next, given the limited sample size and our ambition to describe relationships among the variables that may exist across a diverse sample of graduate students, we conducted a bivariate analysis, using correlation analysis, to identify significant relationships between each of the measures of social support and the one dependent

TABLE 2. Descriptive statistics of the social support measures, science identity measure, and persistence measure

\begin{tabular}{|c|c|c|c|c|c|c|}
\hline & $\begin{array}{c}\text { Instrumental } \\
\text { support }\end{array}$ & $\begin{array}{l}\text { Psychosocial } \\
\text { support }\end{array}$ & $\begin{array}{c}\text { Professional } \\
\text { network support }\end{array}$ & $\begin{array}{c}\text { Friend and family } \\
\text { support }\end{array}$ & Science identity & Persistence \\
\hline & $\begin{array}{c}\mathrm{M} \\
(\mathrm{SD})\end{array}$ & $\begin{array}{c}\mathrm{M} \\
(\mathrm{SD})\end{array}$ & $\begin{array}{c}\mathrm{M} \\
(\mathrm{SD})\end{array}$ & $\begin{array}{c}\mathrm{M} \\
(\mathrm{SD})\end{array}$ & $\begin{array}{c}M \\
\text { (SD) }\end{array}$ & $\begin{array}{c}\mathrm{M} \\
(\mathrm{SD})\end{array}$ \\
\hline Group & $\alpha$ & $\alpha$ & $\alpha$ & $\alpha$ & $\alpha$ & $\alpha$ \\
\hline $\begin{array}{l}\text { Full sample } \\
(N=101)\end{array}$ & $\begin{array}{c}3.87 \\
(0.88) \\
0.89\end{array}$ & $\begin{array}{c}3.51 \\
(1.03) \\
0.88\end{array}$ & $\begin{array}{c}3.82 \\
(1.05) \\
0.83\end{array}$ & $\begin{array}{c}5.14 \\
(0.89) \\
0.69\end{array}$ & $\begin{array}{c}4.67 \\
(0.86) \\
0.83\end{array}$ & $\begin{array}{c}7.00 \\
(2.14) \\
0.91\end{array}$ \\
\hline $\begin{array}{l}\mathrm{HU} \\
(N=55)\end{array}$ & $\begin{array}{c}3.84 \\
(0.86) \\
0.88\end{array}$ & $\begin{array}{c}3.53 \\
(0.91) \\
0.82\end{array}$ & $\begin{array}{c}3.74 \\
(1.06) \\
0.82\end{array}$ & $\begin{array}{c}5.09 \\
(0.96) \\
0.67\end{array}$ & $\begin{array}{c}4.62 \\
(0.91) \\
0.75\end{array}$ & $\begin{array}{c}7.16 \\
(2.19) \\
0.92\end{array}$ \\
\hline $\begin{array}{l}\text { Majority } \\
(N=46)\end{array}$ & $\begin{array}{c}3.90 \\
(0.91) \\
0.90\end{array}$ & $\begin{array}{c}3.49 \\
(1.14) \\
0.92\end{array}$ & $\begin{array}{c}3.90 \\
(1.05) \\
0.84\end{array}$ & $\begin{array}{c}5.21 \\
(0.81) \\
0.70\end{array}$ & $\begin{array}{c}4.73 \\
(0.78) \\
0.90\end{array}$ & $\begin{array}{c}6.81 \\
(2.10) \\
0.89\end{array}$ \\
\hline
\end{tabular}


TABLE 3. Correlations among predictor, mediator, and outcome variables of majority doctoral students

\begin{tabular}{lllllll}
\hline & $\mathbf{1}$ & $\mathbf{2}$ & $\mathbf{3}$ & $\mathbf{4}$ & $\mathbf{5}$ \\
\hline Instrumental support (1) & 1 & & & & \\
Psychosocial support (2) & $0.675^{* *}$ & 1 & & & \\
Professional network support (3) & $0.514^{* *}$ & $0.548^{* *}$ & 1 & & \\
Friend and family support (4) & -0.033 & 0.026 & 0.028 & 1 & & \\
Science identity (5) & 0.165 & 0.028 & $0.357^{*}$ & $0.383^{* *}$ & 1 & $0.440^{* * *}$ \\
Persistence (6) & 0.083 & 0.049 & 0.073 & 0.185 & 1 \\
\hline
\end{tabular}

*p $<0.05$.

$* * p<0.01$

variable, "intentions to persist." To test the statistical significance of the indirect effect (i.e., mediated effect) for each model, Preacher and Hayes's bootstrapping method with 5000 resamples was conducted using the mediate function added to SPSS (PROCESS215; Hayes, 2013). Point estimates and confidence intervals were determined to assess the significance or nonsignificance of the mediated effect. If the estimates indicated that zero did not fall between the confidence intervals, significant mediation effects were found. We completed two separate analyses, one with HU students and one with majority students, to determine whether science identity mediated the relationships between measures of social supports and intentions to persist in a biomedical field (MacKinnon and Pirlott, 2015).

The resampling procedure we used has the advantage of possessing fewer assumptions compared with the Sobel test, which requires the indirect effect to be normally distributed (Preacher and Hayes, 2008; Hayes, 2009). In summary, the PROCESS analyses approach to testing mediation does not require normality assumptions be met (i.e., it is a nonparametric test) and has increased power, which is particularly recommended for smaller sample sizes such as found in our study (Preacher and Hayes, 2004, 2008). Further, unlike Baron and Kenny's (1986) causal mediation procedures, Preacher and Hayes's bootstrapping method does not require the independent variable $(X)$ to be significantly associated with the dependent variable $(Y ; c$ path) for mediation to occur, because the total effect between $X$ and $Y$ includes both direct and indirect effects. In other words, the association between $X$ and $Y$ is allowed to exist through the indirect effects of one or more mediators, yielding a nonsignificant direct effect in the process.

While all participants completed each survey used in the analyses, we used listwise deletion in SPSS for the analysis of all cases in which a data point was missing. This is a common practice when the missing data is relatively small (less than $5 \%$ of the sample) and the missingness is random (Allison, 2001).

\section{RESULTS}

\section{HU and Majority Student Experiences}

The analysis began with testing for significant differences between HU and majority students on all variables of interest. Overall, the results showed that there were no significant differences between these two groups on any of the relevant variables (see Supplemental Tables 1 and 2), except for one descriptive variable regarding preparation of scientific manuscripts. We next sought to address the first research question and test to what extent experiences of social support predicted intentions to persist in biomedical fields among HU and majority doctoral students 1 year later. To answer this, we conducted correlations between measures of social supports (measured at baseline) with intentions to persist 1 year later (see Tables 3 and 4). No significant direct relationships were found for HU or majority students between social support measures at baseline and intentions to persist in science a year later. In contrast, correlational results showed a significant direct relationship between science identity 1 year later and intentions to persist in biomedical careers 1 year later for both HU $(r=0.29$; $p<0.01)$ and majority $(r=0.44 ; p<0.01)$ students. In addition, the results showed significant relationships between science identity and both friend and family support $(r=0.38 ; p<0.01)$ and professional network support $(r=0.36$; $p<0.05)$ for majority students. While for HU students, there were significant relationships between science identity and instrumental ( $r=0.46 ; p<0.01)$, psychosocial $(r=0.40 ; p<0.01)$, and family and friend $(r=0.29 ; p<0.01)$ support. Overall, the types of social support related to science identity were largely different for HU and majority doctoral students.

\section{PROCESS Mediation Results}

Next, we sought to answer the research question "To what extent does support that is accompanied by increased science identity predict persistence?" In other words, does science identity mediate the relationship between forms of social

TABLE 4. Correlations among predictor, mediator, and outcome variables of $\mathrm{HU}$ doctoral students

\begin{tabular}{lllccc}
\hline & $\mathbf{1}$ & $\mathbf{2}$ & $\mathbf{3}$ & $\mathbf{4}$ & $\mathbf{5}$ \\
\hline Instrumental support (1) & 1 & & & & \\
Psychosocial support (2) & $0.651^{* *}$ & 1 & & & \\
Professional network support (3) & 0.245 & 0.184 & 1 & & \\
Friend and family support (4) & 0.256 & 0.196 & -0.062 & 1 & \\
Science identity (5) & $0.460^{* *}$ & $0.398^{* *}$ & 0.191 & $0.293^{* *}$ & 1 \\
Persistence (6) & -0.166 & -0.023 & -0.066 & -0.044 & $0.288^{* * *}$ \\
\hline
\end{tabular}

** $p<0.01$. 


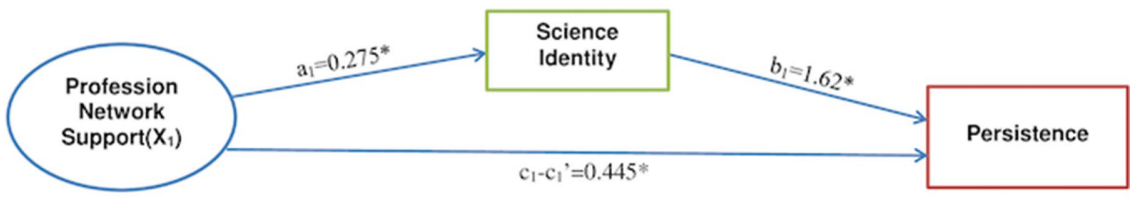

FIGURE 2. Majority doctoral student PROCESS mediation outcome. This figure shows that, among the majority doctoral students, professional network support significantly influences persistence through science identity. $a_{\mathrm{i}}$ represents estimated direct effect of social support measure on science identity; $b_{i}$ represents estimated direct effect of science identity on persistence; and $c_{i}-c_{i}^{\prime}$ represents the estimated mediated effect the social support measure has on persistence.

supports and intentions to persist? To test this, we conducted PROCESS mediation analyses for HU and majority students following the criteria and procedures that Hayes (2013) describes testing the relationships depicted in Figure 1 (Hayes, 2013). Given these results, one PROCESS mediation model was performed for majority students, using professional network support as the independent variable shown in Figure 2. Three PROCESS mediation models were executed for HU students, using psychosocial, instrumental, and friend and family support as independent variables, as shown in Figure 3.

Professional network support and Majority Students. Our first analysis examined professional network support. As shown in Figure 2, for majority students, we found that professional network support $\left(X_{1}\right)$ affected persistence $(Y): c_{1}=0.149(\mathrm{SE}=$ $0.324, t=0.459, p=0.649)$. $X_{1}$ also affected the science identity $(M): a_{1}=0.275(\mathrm{SE}=0.130, t=2.12, p=0.040)$. Science identity $(M)$ also affected the mediator science $Y: b_{1}=1.62$ (SE $=0.308, t=5.24, p<0.001)$, even when adjusted for $X_{1}$. The adjusted effect $X_{1}$ is $c_{1}^{\prime}=-0.296$ (SE $=0.264, t=-1.12, p=$ $0.269)$, when including $M$. The mediated effect estimate as $c$ $-c_{1}^{\prime}=0.445$ with $95 \%$ confidence interval (CI) $[0.062,1.02]$

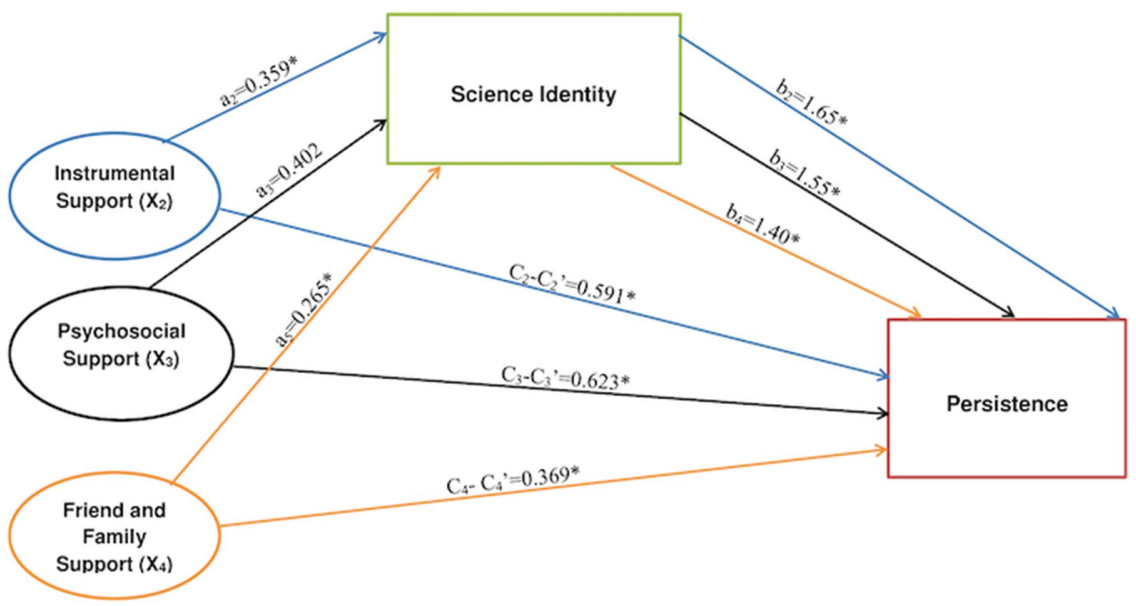

FIGURE 3. HU doctoral student PROCESS mediation outcome. This figure shows that, among HU doctoral students, psychosocial, instrumental, and family and friend support significantly influence persistence through science identity, respectively. $a_{i}$ represents estimated direct effect of social support measure on science identity; $b_{i}$ represents estimated direct effect of science identity on persistence; and $c_{i}-c_{i}^{\prime}$ represents the estimated mediated effect the social support measure has on persistence. and Preacher's $\kappa_{1}^{2}=0.255$, showing the mediated effect was statistically significant for majority students (Figure 2). The mediation was insignificant for HU students.

Instrumental Support and HU Students. As shown in Figure 3, mediation of science identity on the relationship of instrumental support and persistence was significant for HU students. The instrumental support $X_{2}$ affected persistence $(Y)$, without the influence of science identity $(M), c_{2}=$ $-0.441(\mathrm{SE}=0.419, t=-1.05, p=0.300)$, and it affected $M: a_{2}=0.359(\mathrm{SE}=0.123, t=2.91, p=0.006)$. $M$ affected $Y: b_{2}=1.65(\mathrm{SE}=0.484, t=3.41, p=0.002)$, adjusting for $X_{2}$. When $M$ was included in the model, the effect of $X_{2}$ on $Y$ dropped to $c_{2}^{\prime}=-1.03$ ( $\mathrm{SE}=0.410, t=-2.51$, $p=0.016$ ). The mediated effect is estimated as $c_{2}-c_{2}^{\prime}=0.591$ with 95\% CI $[0.163,1.40]$. Science identity significantly mediated the effect (Preacher's $\kappa_{2}^{2}=0.238$ ) on the relationship of instrumental support predicting persistence for HU students (Figure 3). The mediation was insignificant for majority students.

Psychosocial Support and HU Students. Next, we determined whether science identity mediated the relationship between advisor psychosocial support and persistence. The advisor psychosocial support $X_{3}$ affected $Y$, without the influence of $M, c_{3}=-0.058$ (SE $=0.406, t=-0.143, p=0.887$ ), and it affected $M: a_{3}=0.402$ (SE $\left.=0.113, t=3.57, p=0.001\right) . M$ affected $Y: b_{3}=1.55(\mathrm{SE}=0.528, t=2.94, p=0.006)$, adjusting for $X_{3}$. When $M$ was included in the model, the effect of $X_{3}$ on $Y$ dropped to $c_{3}^{\prime}=-0.681$ ( $\left.\mathrm{SE}=0.428, t=-1.59, p=0.120\right)$. The mediated effect is estimated as $c_{3}-c_{3}^{\prime}=0.623$ with $95 \% \mathrm{CI}$ $[0.202,1.25]$; this means science identity had a significant mediated effect (Preacher's $\kappa_{3}^{2}=0.231$ ) on the relationship of psychosocial support predicting persistence (Figure 3). The mediation was insignificant for majority students.

Friend and Family Support and HU Students. Finally, we determined whether science identity mediated the relationship between friend and family support and persistence. The friend and family support $X_{4}$ affected persistence $(Y)$, without the influence of science identity $(M), c_{4}=$ -0.109 (SE $=0.363, t=-0.299, p=$ 0.766 ), and it affected $M: a_{4}=0.265$ (SE $=$ $0.109, t=2.43, p=0.020) . M$ affected $Y$ : $b_{4}=1.40(\mathrm{SE}=0.446, t=3.13, p=0.003)$, adjusting for $X_{4}$. When $M$ was included in the model, the effect of $X_{4}$ on $Y$ dropped to $c_{4}^{\prime}=-0.478(\mathrm{SE}=0.353, t=-1.35, p=$ $0.183)$. The mediated effect is estimated as $c_{4}-c_{4}^{\prime}=0.369$ with $95 \%$ CI [0.067, 0.896]; this means science identity has a significant mediated effect (Preacher's $\left.\kappa_{4}^{2}=0.154\right)$ on the relationship of friend and family support predicting persistence 
(Figure 3). The mediation was insignificant for majority students.

\section{DISCUSSION}

This 1-year longitudinal study with HU and majority biomedical doctoral students found that both similarities and differences exist between these two populations. To begin, all students, regardless of majority/HU status, reported largely equivalent experiences of social support, science identity, and intentions to persist relative to each other. This indicates that HU students are not experiencing significantly more or less social support than their fellow students and that differences that do exist do not influence their overall intentions to persist in biomedical fields among this population of UCSF doctoral students. Results also showed that, for all students, the various types of social support did not directly predict intentions to persist in biomedical fields 1 year later. Specifically, a student's perceived support from mentors, advisors, and friend and family did not directly predict intentions to persist in biomedical careers 1 year later for HU students or majority doctoral students. Despite previous research suggesting that social support might directly and differentially influence HU students' persistence to a greater extent than majority students, the results of this yearlong study did not corroborate that hypothesis.

Consistent with previous findings, however, the results did indicate that science identity was significantly related to intentions to persist for both HU and majority students. The results are consistent with research findings that demonstrate that students' embracing their professional identities remains a key factor related to biomedical science career persistence among undergraduates and graduate students (Villarejo and Barlow, 2007; Hurtado et al., 2009; Chemers et al., 2011; Hernandez et al., 2013). The study results indicate that, overall, HU and majority students at UCSF had a lot of commonality in reported experiences and in how their experiences of social support and science identity independently related to their intentions to persist a year later.

\section{Nuances}

The lack of significant direct relationships between social supports and intentions to persist was surprising, given that measures of quality mentorship (which sometimes included psychosocial, instrumental, and networking support) had previously been found to significantly predict higher intentions to persist in STEM careers (Hernandez et al., 2017). However, previous research had primarily focused on HU undergraduate students in science training programs from less competitive universities. In contrast, data from the HU and majority doctoral students attending a highly competitive university show that there can be nuances in the relationship. In answering the third research question- "Does science identity mediate the relationship between several forms of social support and intentions to persist in biomedical career pathways?"-these nuances became clearer.

While both HU and majority doctoral students indicated that some types of social support predicted future science identity, these groups differed in which specific types of support significantly related to science identity 1 year later. These differences are more fully understood by examining the results of the mediation analyses, which indicate that, for HU students, science identity more often mediates the relationship between social supports and biomedical career persistence. Specifically, for HU students, when advisors provided psychosocial or instrumental support that strengthened science identity, students were more likely to also report higher intentions to persist. This was also true for friend and family support. The significant mediations strongly suggest that a variety of social supports are important to HU students' persistence vis-à-vis contributing toward building a professional science identity and that this ultimately results in intentions to persist. Previous research has shown that HU students' experiences of belonging and connection (also referred to as "social cohesion") to their academic community is complex and often hindered by the campus racial climate (Hurtado and Carter, 1997). The differential outcomes for HU and majority students in this study may simply reflect that the building of a professional identity benefits from multiple sources of support when in an environment that does not readily convey cues of belonging. Alternatively, there may be cultural differences that leave HU students to more greatly value social connections than majority students. However, given that the majority group included Asian students, who come from cultures typically categorized as using collectivistic concepts of self that are similar to those of HU students (Markus and Kitayama, 1991), the latter explanation seems unlikely. Differential experiences of prejudice and racism may also influence the valuing of social connection. Future research is needed to better understand what aspects of the higher education context and students' cultures contribute toward these differential social support influences.

In contrast, for majority students, science identity only mediated the relationship between professional network support and intentions to persist. Thus, the mediation results indicate that HU and majority students do not share common needs in terms of support from advisors and friend and family when it comes to maintaining or growing their professional identities in a way that results in intentions to persist in their professional fields. For majority students, professional network support was important in forming science identity, whereas for HU students, other forms of support (including psychosocial, instrumental, and friend and family) were important.

The results of this study advance our understanding of why and for whom social support impacts persistence in biomedical fields. These results suggest that social support has an impact on persistence because of its ability to enhance the development of science identity. And the results also show this is particularly true for HU students. These findings are consistent with the previous theory that HU students have a different experience in academia than majority students (Estrada et al., 2018a). Further, the findings are consistent with research on science intervention programs that indicate that support and quality mentorship (which include instrumental and psychosocial support) are more likely to result in HU persistence than when these elements are lacking (Hernandez et al., 2017). Finally, our findings extend the definition of social support to include family and friend support as another important source for HU students. This is consistent with previous research showing that HU students typically hold more communal values and value community to a greater extent than majority students (Oyserman et al., 2002; Brown, 2008). For majority students, having an advisor who provides professional network support 
also appears to be important. Thus, while all students need support in maintaining their social identities, minority or majority status in a student's educational context may impact the type of support needed.

\section{Caveats}

Persistence in this study was measured by five questions asking about the intention to pursue biomedical careers. This sort of measure has been used in previous research with undergraduates and has been shown to relate to application to and enrollment in graduate science programs, as well as engagement in conducting research (Estrada et al., 2011). This is consistent with previous research findings that intentions do predict behavior when questions are specific to the predicted behavior, as opposed to being vague (Kaiser and Wilson, 2004). Further, there is strong evidence that, when students set a goal to persist in science, this does relate to longer-term persistent behaviors and successful performance in science-related occupations (Luzzo et al., 1999; Sullivan and Mahalik, 2000; Lent et al., 2003a). Thus, while intention is not the equivalent of actual behavioral persistence years later, it is a strong proximal indicator of it.

A second caveat to consider is that this study took place at an elite university's graduate program. The results, therefore, may not translate to less competitive cohorts of students or undergraduate or postdoctoral populations. As can be seen in students' baseline levels of intentions to pursue biomedical careers, the doctoral students in this study were highly committed to biomedical research career paths. In cases such as this, persistence does not rely on students increasing their commitment, but on students maintaining their commitment. Research with undergraduates has shown that freshman HU students who enter university with a high interest in science often experience significant declines in interest after 1 year as an undergraduate compared with majority students (Hurtado et al., 2009). Future research is needed to examine whether this is also true for doctoral students. Further, differences among year cohorts and types of degree programs (and the intersection of these) in graduate school was not examined in this paper due to insufficient power. Perhaps types of social support vary according to year in graduate school or discipline. Future research that includes larger sample sizes of graduate students would contribute toward advancing knowledge regarding these issues.

Finally, it is worth noting that the HU students in this study represented various ethnic groups, some of which are not traditionally categorized as underrepresented by federal agencies. However, all of the students shared in common self-identification as HU students and were navigating their career pathways with that identity. Additionally, even though we oversampled for HU students, there was not enough power to statistically test for subgroup differences, such as differences between Latinx and African-American students. The findings simply indicate that, overall, a variety of social supports are important for HU students' persistence. Future research with larger sample sizes may be able to better discern whether inter-ethnic group differences exist.

\section{CONCLUSION}

This study suggests having an advisor who provides professional network support, as well as friend and family, may be important sources of influence for HU doctoral students' persistence. Further, these findings indicate that this is especially true when social support bolsters feelings of identifying with the professional community in which they seek to belong. Based on the findings of this study (and keeping in mind that these are not equally influential for HU and majority students) specific types of support that faculty and advisors can provide include the following:

- Psychosocial supports such as assisting students in creating and completing individual development plans (for a detailed discussion of this, see Tsai et al., 2018), supporting students in maintaining healthy school/work-life balance, and being willing to provide advice on nonacademic career opportunities.

- Instrumental supports such as providing helpful feedback on students' scientific work, meeting with students frequently enough to support student needs, and maintaining a respectful level of communications.

- Professional networking supports such as helping students to meet other professionals in the field inside and outside of the institution.

At the same time, staying supportive of students' connections to friends and family, particularly for HU students, can be important. In some cases, this may require greater flexibility, such as when students need to return home to partake in cultural traditions and rituals around births, coming of age, marriage or death. Additionally, supporting HU students' engagement in professional clubs and societies may provide communities of inclusive research practice. These recommendations are not exhaustive but build from the results presented in this paper. Other research on mentorship in nonacademic and academic settings strongly suggests that a key variable is that mentors and protégés share a common understanding about what is supportive (Waters, 2004) and, when possible, have agreement around expectations and experiences. Further, training for all personsstudents, mentors, and peer supports - can improve the quality of the support experienced (Lewis et al., 2017), for example, working together to create a student development plan (Tsai et al., 2018). Overall, these recommendations point toward a more communal approach to academia and suggest there may be costs to assuming people should "go it alone."

\section{ACKNOWLEDGMENTS}

This study was funded by a grant (RO1GM107782-01) provided by the National Institute of General Medical Sciences. We are grateful to the members of the advisory board and stakeholders who graciously shared their expert advice. We also deeply appreciate the Graduate Study Division, School of Medicine, and School of Nursing at UCSF for their support and assistance in this project. A special note of thanks to the study participants for their enthusiastic participation in the various aspects of this study.

\section{REFERENCES}

Allison, P. D. (2001). Missing data (Vol. 136). Thousand Oaks, CA: Sage.

Baron, R. M., \& Kenny, D. A. (1986). The moderator-mediator variable distinction in social psychological research: Conceptual, strategic, and statistical considerations. Journal of Personality and Social Psychology, 51(6), 1173 
Blake-Beard, S., Bayne, M. L., Crosby, F. J., \& Muller, C. B. (2011). Matching by race and gender in mentoring relationships: Keeping our eyes on the prize. Journal of Social Issues, 67(3), 622-643.

Brown, A. V. (2008). Effectively educating Latino/a students: A comparative study of participation patterns of Hispanic American and Anglo-American university students. Journal of Hispanic Higher Education, 7(2), 97-118.

Chemers, M. M., Zurbriggen, E. L., Syed, M., Goza, B. K., \& Bearman, S. (2011). The role of efficacy and identity in science career commitment among underrepresented minority students. Journal of Social Sciences, 67(3), 469-491.

Corwin, L. A., Graham, M. J., \& Dolan, E. L. (2015). Modeling course-based undergraduate research experiences: An agenda for future research and evaluation. CBE-Life Sciences Education, 14(1), es1. doi: 10.1187/ cbe.14-10-0167

Dolan, E., \& Johnson, D. (2009). Toward a holistic view of undergraduate research experiences: An exploratory study of impact on graduate/ postdoctoral mentors. Journal of Science Education and Technology, 18(6), 487.

Eby, L. T., Allen, T. D., Hoffman, B. J., Baranik, L. E., Sauer, J. B., Baldwin, S., ... \& Evans, S. C. (2013). An interdisciplinary meta-analysis of the potential antecedents, correlates, and consequences of protégé perceptions of mentoring. Psychological Bulletin, 139(2), 441-476. doi: 10.1037/a0029279

Eby, L. T., Rhodes, J. E., \& Allen, T. D. (2007). Definition and evolution of mentoring. In Allen, T. D., \& Eby, L. T. (Eds.), The Blackwell handbook of mentoring: A multiple perspectives approach (pp. 7-20). Oxford, UK: Wiley-Blackwell.

Espinosa, L. (2011). Pipelines and pathways: Women of color in undergraduate STEM majors and the college experiences that contribute to persistence. Harvard Educational Review, 81(2), 209-241.

Estrada, M. (2014). Ingredients for improving the culture of STEM degree attainment with co-curricular supports for underrepresented minority students (Commissioned paper for National Academies of Science, Engineering, and Medicine). Retrieved August 9, 2019, from http://sites. nationalacademies.org/cs/groups/dbassesite/documents/webpage/ dbasse_088832.pdf

Estrada, M., Eroy-Reveles, A., \& Matsui, J. (2018a). The influence of affirming kindness and community on broadening participation in STEM career pathways. Social Issues and Policy Review, 12(1), 258-297. doi: 10.1111/ sipr.12046

Estrada, M., Hernandez, P. R., \& Schultz, P. W. (2018b). A longitudinal study of how quality mentorship and research experience integrate underrepresented minorities into STEM careers. CBE-Life Sciences Education, 17(1), ar9. doi: 10.1187/cbe.17-04-0066

Estrada, M., Woodcock, A., Hernandez, P. R., \& Schultz, P. W. (2011). Toward a model of social influence that explains minority student integration into the scientific community. Journal of Educational Psychology, 103(1), 206-222. doi: 10.1037/a0020743

Estrada, M., Woodcock, A., \& Schultz, P. W. (2014). Tailored panel management: A theory-based approach to building and maintaining participant commitment to a longitudinal study. Evaluation Review, 38(1), 3-28. doi: 10.1177/0193841×14524956

Flaxman, E., Ascher, C., \& Harrington, C. (1988). Youth mentoring: Programs and practices (Urban Diversity Series No. 97). ERIC Clearinghouse on Urban Education. Retrieved August 9, 2019, from https://eric.ed.gov/ ?id=ED308257

Graham, M. J., Frederick, J., Byars-Winston, A., Hunter, A. B., \& Handelsman, J. (2013). Science education. Increasing persistence of college students in STEM. Science, 341(6153), 1455-1456. doi: 10.1126/science.1240487

Hayes, A. F. (2009). Beyond Baron and Kenny: Statistical mediation analysis in the new millennium. Communication Monographs, 76(4), 408-420.

Hayes, A. F. (2013). Introduction to mediation, moderation, and conditional process analysis: A regression-based approach. New York: Guilford.

Hernandez, P. R., Estrada, M., Woodcock, A., \& Schultz, P. W. (2017). Protégé perceptions of high mentorship quality depend on shared values more than on demographic match. Journal of Experimental Education, 85(3), $450-468$.

Hernandez, P. R., Schultz, P., Estrada, M., Woodcock, A., \& Chance, R. C. (2013). Sustaining optimal motivation: A longitudinal analysis of interventions to broaden participation of underrepresented students in STEM. Journal of Educational Psychology, 105(1), 89.
Hurtado, S., Cabrera, N. L., Lin, M. H., Arellano, L., \& Espinosa, L. L. (2009) Diversifying science: Underrepresented student experiences in structured research programs. Research in Higher Education, 50(2), 189-214. doi: 10.1007/s11162-008-9114-7

Hurtado, S., \& Carter, D. F. (1997). Effects of college transition and perceptions of the campus racial climate on Latino college students' sense of belonging. Sociology of Education, 70(4), 324-345.

Kaiser, F. G., \& Wilson, M. (2004). Goal-directed conservation behavior: The specific composition of a general performance. Personality and Individual Differences, 36(7), 1531-1544

Kelman, H. C. (2006). Interests, relationships, identities: Three central issues for individuals and groups in negotiating their social environment. Annual Review of Psychology, 57, 1-26.

Larson, R. C., Ghaffarzadegan, N., \& Xue, Y. (2014). Too many PhD graduates or too few academic job openings: The basic reproductive number RO in academia. Systems Research and Behavioral Science, 31(6), 745-750.

Laursen, S., Hunter, A., Seymour, E., Thiry, H., \& Melton, G. (2010). Undergraduate research in the sciences: Engaging students in real science. Hoboken, NJ: Wiley.

Lent, R. W., Brown, S. D., Nota, L., \& Soresi, S. (2003a). Testing social cognitive interest and choice hypotheses across Holland types in Italian high school students. Journal of Vocational Behavior, 62(1), 101-118.

Lent, R. W., Brown, S. D., Schmidt, J., Brenner, B., Lyons, H., \& Treistman, D. (2003b). Relation of contextual supports and barriers to choice behavior in engineering majors: Test of alternative social cognitive models. Journal of Counseling Psychology, 50(4), 458.

Lewis, V., Martina, C. A., McDermott, M. P., Chaudron, L., Trief, P. M. LaGuardia, J. G., ... \& Ryan, R. M. (2017). Mentoring interventions for underrepresented scholars in biomedical and behavioral sciences: Effects on quality of mentoring interactions and discussions. CBE-Life Sciences Education, 16(3), ar44

Lopatto, D. (2007). Undergraduate research experiences support science career decisions and active learning. CBE-Life Sciences Education, 6(4), 297-306.

Luzzo, D. A., Hasper, P., Albert, K. A., Bibby, M. A., \& Martinelli, E. A., Jr. (1999). Effects of self-efficacy-enhancing interventions on the math/science self-efficacy and career interests, goals, and actions of career undecided college students. Journal of Counseling Psychology, 46(2), 233.

Mackinnon, D. P., \& Pirlott, A. G. (2015). Statistical approaches for enhancing causal interpretation of the $M$ to $Y$ relation in mediation analysis. Personality and Social Psychology Review, 19(1), 30-43.

Markus, H, \& Kitayama, S. (1991). Culture and the self: Implications for cognition, emotion and motivation. Psychological Review, 98(2), 224-253.

Mendoza-Denton, R., Page-Gould, E., \& Pietrzak, J. (2006). Mechanisms for coping with status-based rejection expectations. In Levin, S., \& Van Laar, C. (Eds.), Stigma and group inequality: Social psychological perspectives (pp. 151-170). Mahwah, NJ: Lawrence Erlbaum Associates.

Meyers, L. C., Brown, A. M., Moneta-Koehler, L., \& Chalkley, R. (2018). Survey of checkpoints along the pathway to diverse biomedical research faculty. PLOS ONE, 13(1), e0190606.

Nakkula, M. J., \& Harris, J. T. (2014). Assessing mentoring relationships. In DuBois, D. L., \& Karcher, M. J. (Eds.), Handbook of youth mentoring (2nd ed., pp. 45-62). Thousand Oaks, CA: Sage.

National Academies of Sciences, Engineering, and Medicine. (2017). Undergraduate research experiences for STEM students: Successes, challenges, and opportunities. Washington, DC: National Academies Press.

National Institutes of Health (NIH). (2012). Biomedical Research Workforce Working Group report. Retrieved August 9, 2019, from https://acd.od .nih.gov/documents/reports/Biomedical_research_wgreport.pdf

$\mathrm{NIH}$. (n.d.). Thoughts on choosing a research mentor. Retrieved August 9 , 2019, from www.training.nih.gov/mentoring_guidelines

National Research Council. (2011). Research training in the biomedical, behavioral, and clinical research sciences. Washington, DC: National Academies Press.

Nelson, D. J., \& Brammer, C. N. (2010). A national analysis of MINORITIES in science and engineering faculties at research universities (2nd ed.) (Table 56). Retrieved August 9, 2019, from www.cssia.org/pdf/ 20000003-ANationalAnalysisofMinoritiesinScienceandEngineering FacultiesatResearchUniversities.pdf 
Nunnally, J., \& Bernstein, I. (1994). Psychometric theory (3rd ed.). New York: McGraw-Hill.

Oyserman, D., Coon, H. M., \& Kemmelmeier, M. (2002). Rethinking individualism and collectivism: Evaluation of theoretical assumptions and meta-analyses. Psychological Bulletin, 128(1), 3-72.

Preacher, K. J., \& Hayes, A. F. (2004). SPSS and SAS procedures for estimating indirect effects in simple mediation models. Behavior Research Methods, Instruments, and Computers, 36(4), 717-731. doi: 10.3758/ BF03206553

Preacher, K. J., \& Hayes, A. F. (2008). Asymptotic and resampling strategies for assessing and comparing indirect effects in multiple mediator models. Behavior Research Methods, 40(3), 879-891.

President's Council of Advisors on Science and Technology (PCAST). (2012). Engage to excel: Producing one million additional college graduates with degrees in science, technology, engineering, and mathematics. Retrieved August 9, 2019, from https://obamawhitehouse.archives.gov/ sites/default/files/microsites/ostp/pcast-engage-to-excel-final -2-25-12.pdf

Rockey, S. (2012a). So, what does the biomedical research workforce look like? Rock Talk. Retrieved August 9, 2019, from https://nexus.od.nih.gov/ all/2012/06/22/so-what-does-the-biomedical-research-workforce -look-like/

Rockey, S. (2012b). What we've learned about graduate students. Rock Talk. Retrieved August 9, 2019, from https://nexus.od.nih.gov/all/2012/06/27/ what-weve-learned-about-graduate-students/
Sinche, M., Layton, R. L., Brandt, P. D., O'Connell, A. B., Hall, J. D., Freeman, A. M., ... \& Brennwald, P. J. (2017). An evidence-based evaluation of transferrable skills and job satisfaction for science PhDs. PLOS ONE, 12(9), e0185023. doi: hTtps://doi.org/10.1371/journal.pone.0185023

Smolka, A. J., Halushka, P. V., \& Garrett-Mayer, E. (2015). The faculty costs to educate a biomedical sciences graduate student. CBE-Life Sciences Education, 14(1), ar3. doi: 10.1187/cbe.14-06-0106

Sullivan, K. R., \& Mahalik, J. R. (2000). Increasing career self-efficacy for women: Evaluating a group intervention. Journal of Counseling \& Development, 78(1), 54-62.

Tajfel, H., \& Turner, J. C. (2004). The social identity theory of intergroup behavior. In Jost, J. T., \& Sidanius, J. (Eds.), Political psychology: Key readings (Vol. 13, pp. 276-293). New York: Psychology Press.

Thiry, H., \& Laursen, S. L. (2011). The role of student-advisor interactions in apprenticing undergraduate researchers into a scientific community of practice. Journal of Science Education and Technology, 20(6), 771-784.

Tsai, J. W., Vanderford, N. L., \& Muindi, F. (2018). Optimizing the utility of the individual development plan for trainees in the biosciences. Nature Biotechnology, 36(6), 552-553.

Villarejo, M., \& Barlow, A. E. (2007). Evolution and evaluation of a biology enrichment program for minorities. Journal of Women and Minorities in Science and Engineering, 13(2), 119-144.

Waters, L. (2004). Protégé-mentor agreement about the provision of psychosocial support: The mentoring relationship, personality, and workload. Journal of Vocational Behavior, 65(3), 519-532. 